\title{
PROFESSORES $\in$ AGENTES DE LETRAMENTO: IDENTIDADE E POSICIONAMENTO SOCIAL
}

\author{
Angela B. Kleiman
}

\begin{abstract}
RESUMO: O artigo contrasta as noções de professor alfabetizador e agente de letramento, que estariam relacionadas aos distintos modos de aquisição de escrita de professores e educadores populares. Partindo de uma concepção dialógica e interacionista da linguagem, apresentamos dados que mostram como professores e educadores populares se representam e se posicionam em relação aos interlocutores acadêmicos, e argumentamos que as diferenças apontam para modos distintos de construção das identidades relacionais situadas.
\end{abstract}

PALAVRAS-CHAVE: Formação do professor; Letramento acadêmico; Agência social.

\section{INTRODUÇÃO}

Por que sou educador? Qual a minha função? Para a sociedade, para essa criança?....Você até tenta melhorar, ampliar, mas o que acontece? Vem alguém e fecha. Porque você não pode, você tá fora. Você tá ficando à margem..

s professores e alfabetizadores constituem um dos poucos exemplos bem-sucedidos de mobilidade social e econômica através da escolarização e do letramento no Brasil (v. Batista, 1998; Guedes Pinto, 2002). No en-

Universidade de Campinas.

Agradecemos às agências Fapesp e CNPq pelo apoio ao projeto de pesquisa "Formação do Professor: Processos de retextualização e Práticas de Letramento." 
tanto, nos últimos 30 anos, esse grupo tem ficado na mira da mídia, do governo e da universidade, pois teria fracassado na tarefa de democratizar a escola pública ensinando a ler e escrever a todos os que aí chegam. Suas próprias capacidades de ler e escrever são questionadas, toda vez que o país é confrontado com os insatisfatórios resultados dos alunos da escola pública nos testes padronizados, nacionais e internacionais, de leitura. Na busca de figuras de exculpação, os professores ocupam lugar central na complexa e elitista rede de relações sociais brasileira.

Os projetos de pesquisa do Grupo Letramento do Professor ${ }^{1}$ têm por objetivo entender o impacto do letramento nas identidades profissionais dos professores. Este artigo sugere a existência de dois modos de aquisição do letramento, que resultam, grosso modo, em dois tipos de identidades profissionais distintas, a de professor e a de agente de letramento (Kleiman, 2006). As modalidades não estariam necessariamente relacionadas à agência de letramento em que os sujeitos se tornam letrados (escola ou movimento social), embora a trajetória acadêmico-escolar contribua muito frequientemente para a desautoração (disempowering) de seus egressos, ao passo que os movimentos de base social e o engajamento político contribuem para o fortalecimento (empowering ${ }^{2}$ ) de seus membros.

Partindo da premissa de que a formação profissional envolve reposicionamentos sociais que dão forma a uma nova identidade profissional, tentamos entender o que está envolvido nesse processo, tanto nas universidades públicas de prestígio quanto nas faculdades particulares que atendem à população mais pobre. Para tal, temos registrado aulas em cursos de graduação inicial em faculda-

1 Dele fazem parte pesquisadores da PUC-Minas, da Universidade de Taubaté, da Universal Estadual de Bahia, da Universidade Federal de São Carlos e da Unicamp e da ONG Ação Educativa.

2 Os termos empowering e disempowering também têm sido traduzidos para o português, respectivamente, por empoderamento e desempoderamento. 
des particulares e em cursos de formação continuada de universidades públicas, a fim de conhecer as trajetórias de letramento dos seus alunos e entender os significados que atribuem à leitura e escrita, assim como os sentidos que constroem em relação às suas práticas culturais. Investigamos também as estratégias de construção de uma identidade letrada de educadores populares, jovens líderes e outros agentes de letramento comunitários que não estão em processo de profissionalização dentro de universidades, mas dentro dos programas de que tomam parte, ${ }^{3}$ registrando rodas de leitura, debates e outras instâncias de formação. Foram gerados diários, projetos, memoriais, depoimentos, nos diversos processos de formação continuada, em diversas situações, com a finalidade de documentar os movimentos de reposicionamento social nas práticas discursivas em que os sujeitos se engajam.

A noção de agente de letramento está apoiada na premissa de que vir a ser um professor de alfabetização ou um agente envolve questões identitárias relacionadas à aquisição e ao uso da leitura e escritura. Num quadro social que valorize as práticas locais dos grupos minoritários, uma forma de legitimação das práticas do professor envolve a transformação das estratégias dos cursos universitários a fim de educar professores para virem a ser agentes capazes de agir em novos contextos com novas idéias sobre letramento. Nossa pesquisa visa, em última instância, contribuir para essa transformação.

\section{O CONTEXTO DA PESQUISA}

Desde a metade da década de 1990, um conjunto de medidas governamentais visando à melhoria e normatização do sistema educacional pautam o cotidiano do professor. A publicação, em 1997,

Ativistas que usam a escrita para fortalecer sua comunidade; v. Vóvio \& Souza (2005); Ribeiro (2005). 
dos Parâmetros Curriculares Nacionais para o Ensino Fundamental e, em 1999, para o Ensino Médio; o Programa Nacional de Avaliação Permanente do Livro Didático iniciado em 1997; os diversos testes padronizados para avaliar as capacidades de ler, escrever e de usar conhecimentos matemáticos do aluno da escola pública, como o SAEB, e o ENEM; ${ }^{4}$ a exigência de diploma universitário para poder continuar atuando na escola (mesmo nas séries iniciais), obedecendo à Lei de Diretrizes e Bases $n^{\circ}$. 9394, promulgada em 1996, são iniciativas que afligem o já tenso e atribulado dia-a-dia do professor, que encontra dificuldades para entender a linguagem dos documentos oficiais supostamente a eles dirigidos ${ }^{5}$ e para implementar as propostas dos livros didáticos para ele sugeridos, ${ }^{6}$ enquanto corre o risco de ser exonerado ou substituído caso não volte aos bancos escolares para dar início à sua formação universitária.

Soares (1997) aponta a discrepância entre o alfabetizador ideal, pressuposto nos documentos oficiais, e o alfabetizador real, que, até há pouco, era formado em cursos profissionalizantes de nível médio ou em faculdades particulares de baixo prestígio acadêmico, com pouca infra-estrutura e sem tradição de pesquisa. A mídia, geralmente antagônica e crítica do trabalho realizado pelos professores, incrementa os sentimentos de impotência e frustração entre os professores, cujas vozes estão sempre ausentes do debate que lhes diz respeito.

O comentário de uma professora de $4^{\mathrm{a}}$ série, a seguir, ilustra a percepção da impotência do grupo em relação a essas iniciativas:

\footnotetext{
Instituídos em 1997 e 1999, respectivamente.

5 Pesquisa desenvolvida no nosso grupo (ver Borges da Silva, 2001) mostra que as dificuldades se devem a problemas de textualidade dos documentos e não a problemas de leitura dos professores.

6 Porque introduzem novas teorias linguíisticas desconhecidas pelo professor; por exemplo, os parâmetros focalizam textos e gêneros e os professores são formados para trabalhar com palavras e frases.
}

\section{2}


Filol. lingüíst. port., n. 8, p. 409-424, 2006.

(1) Nádia: [o SAEB não avalia adequadamente] porque tá fora da realidade... não condiz com a prática, não condiz com o material adotado, não condiz com a formação do professor, não condiz com a realidade social, não condiz com o bairro, está descontextualizado (...) você não sabe os resultados, você vai saber dali a três anos que em 1997 com a professora Neide ou com a professora Nádia os alunos da $4^{a}$. série saíram-se péssimos. O que pudemos fazer? NADA. ${ }^{7}$

A ausência do pronome de auto-referência $e u$, que imprime subjetividade ao uso da língua, é indicativo de que ela não se vê como uma protagonista em controle do processo de ensino-aprendizagem pelo qual é responsável; os pronomes da $1^{\mathrm{a}}$. pessoa estão ausentes, exceto quando a ação predicada expressa uma incapacidade ou impotência do grupo a que pertence: pudemos fazer? nada. As referências ao enunciador, Nádia, são feitas pelo pronome da segunda pessoa do singular, você, genérico e distante, que inclui o eu que enuncia, mas também uma infinidade de outros - ou pelo nome, professora Nádia, cuja conjugação em $3^{\text {a }}$. pessoa institui a existência de uma entidade aparte, que realiza ações que ficam fora do âmbito de ação, poder ou responsabilidade do enunciador.

O contexto de desvalorização do professor $^{8}$ é pertinente para analisar essas produções discursivas, que relatam ações que são da esfera do professor, mas com sintaxe na qual ele não ocupa o lugar de agente (humano) das ações relatadas. Ele é também relevante para entender os significados que esses professores atribuem a suas práticas de letramento.

Os professores alfabetizadores provêm de famílias que enfatizam pelo menos a importância simbólica de ler e escrever, daí seu sucesso na escola e na obtenção de um grau profissional. Ao fazer

7 Dados coletados por Miriam Retorta. Usamos ortografia e pontuação convencional excetuando em formas informais comuns, como "tá". As demais convenções são: .... Pausa; :::: vogal alongada, em geral indicando ênfase; Maiúsculas: acento enfático; (...) passagem não transcrita.

8 Essa desvalorização do professor teria começado, segundo Soares (1996), na década de 1970 , quando a reforma educacional da Lei $n^{\circ} .5692 / 71$ permitiu o acesso das classes baixas à escola, necessitando de cada vez mais professores. 
isso, eles escapam à norma. Embora concordemos com resultados de pesquisa que indicam que o letramento começa na família e que há diferenças significativas nos modos de usar a linguagem entre famílias de classe trabalhadora e famílias dos grupos majoritários (Heath, 1983), acreditamos ser mais relevante, para a transformação e a mudança, aprender como um caminho singular, individual de sucesso é conseguido, num processo que geralmente representa fracasso para um grupo social (cf. Ribeiro, 2005), em vez de pôr as práticas de letramento de sujeitos mais familiarizados com práticas de leitura de prestígio como o parâmetro ou norma de comparação. Em outras palavras, interessa-nos descobrir, nos seus relatos, como os alfabetizadores subvertem, para usar as palavras de Certeau (1994), a ordem social, fazendo-a colaborar para atingir seus próprios propósitos.

\section{REPRODUÇÃO VS AGÊNCIA}

Uma representação habitual do professor é a de mediador, mas o sentido do senso comum apagou os sentidos originais do conceito, relativos à mediação semiótica na aprendizagem (Vygotsky [1930]1984) e passou a ver o mediador como aquele que está no meio, aquele que medeia, por exemplo, a interação entre autor e leitor, arbitrando sobre significados e interpretações. Daí termos argumentado em favor de uma outra representação, a de agente de letramento (Kleiman, 2006), cujas associações metonímicas com o conceito de agente (humano) trazem à mente a idéia de fazer coisas: um agente se engaja em ações autônomas de uma atividade determinada e é responsável por sua ação, em contraposição ao paciente, recipiente ou objeto, ou ao sujeito coagido.

Se por um lado, todos somos agentes exercendo nossa ação sobre objetos do mundo, pelo fato de sermos humanos, a agência social é uma condição de poucos, aqueles que agem na coletividade, exercendo sua ação nos outros, em função dos objetivos de um 
grupo social. A agência social envolve, segundo Archer (2000, p. 261-7), gente real agindo no mundo social através da ação coletiva. ${ }^{9} \mathrm{Um}$ agente social trabalhando num determinado grupo tem capacidade para articular os interesses partilhados pelos membros da coletividade, organizar o grupo para a ação conjunta, gerar movimentos sociais e exercitar influência, como coletividade, no processo de tomar decisões. Assim, um agente teria a capacidade de decidir sobre um curso de ação, de interagir com outros agentes e seria capaz de modificar ou mudar seus planos segundo as ações, e mudanças resultantes dessas ações, do grupo e faria isso "estrategicamente", de uma forma que não seria entendida como a soma de interesses de membros individuais da coletividade.

A ação estratégica, segundo o autor, implica que agentes sociais são sujeitos ativos com motivações para tentar atingir objetivos, não apenas para agir sobre objetos (Archer, 2000, p. 266). Podemos ir além e adotar o conceito de estratégia de Certeau (1994, p. 46): o cálculo das relações de poder envolvidas que se torna possível quando "um sujeito de querer e poder /.../ postula um lugar capaz de ser circunscrito como um próprio e, portanto, capaz de servir de base a uma gestão de suas relações com uma exterioridade distinta". Segundo o autor, as nacionalidades políticas, científicas e econômicas são construídas com base nesse modelo estratégico; daí podermos pensar que a construção de identidades profissionais, ou de identidades letradas, através da interação, é estratégica, envolvendo posicionamentos capazes de gerar ações que contribuam para a mobilidade social do indivíduo. Assim, as ações estratégicas de um agente de letramento, "o mobilizador primário das capacidades e habilidades do grupo" teriam por objetivo fazer emergir, nas interações com os educandos, seus conhecimentos de

9 Archer (2000) distingue agência primária, no sentido de que todos somos agentes humanos, da noção de agência social, que o autor chama de agência corporativa (corporate agency). 
livros e outros recursos escritos, assim como aqueles das suas redes comunicativas familiares, religiosas e outras, com o objetivo de ajudá-los a atribuir sentido à palavra escrita (Kleiman, 2006). É importante salientar que quando os indivíduos se engajam em ações sociais com objetivos coletivos, visando à transformação, eles se sentem "co-autores da experiência partilhada"; inclusive das mesmas leis que eles contestam e resistem (Heeson, 1997).

A idéia de uma identidade categorial, que o indivíduo carrega de uma situação para outra (cf. Zimermman, 1998) ${ }^{10}$ subjaz à distinção que estamos propondo entre professor e agente de letramento. Ela é construída ao longo do processo de aquisição da escrita, culminando em identidades profissionais que remetem a diversos modos de se relacionar com a cultura reconhecida como mais legítima e de se apropriar de práticas de letramento. Posto que o letramento é situado, local, esses modos de relacionamento são diferenciados. Utilizando a noção de habitus de Bourdieu, Ribeiro (2005) propõe que nos grupos em processo de ascensão social, os grupos dominados podem adotar atitudes de resistência à hierarquia, baseada na valorização da cultura popular, ou atitudes de reconhecimento submisso da superioridade da cultura dos grupos dominantes. Acreditamos que essas duas alternativas orientam, respectivamente, as identidades de, por um lado, educador popular, um agente de letramento com pouca escolaridade formal, em geral apreendida de forma assistemática, via processos de ação política em associações de bairro, sindicatos e outras agrupações sociais que incorporam o letramento de seus membros e, por outro lado, professor alfabetizador, egresso de curso superior do sistema formal de educação e portanto, altamente escolarizado, após um longo período de esforço sistemático, disciplinado, individual.

10 Zimmerman (1998, p. 90) define as identidades "transportáveis (transportable identities) como aquelas que viajam com os indivíduos de situação em situação e são potencialmente relevantes para qualquer situação e em qualquer interação. 
Filol. lingüíst. port., n. 8, p. 409-424, 2006.

Os processos que contribuem para essas construções identitárias são discursivos. Se aceitamos a premissa de que a linguagem constitui o sujeito que, por sua vez, a constitui, as identidades profissionais - vir a ser professor, advogado, engenheiro - são construídas discursivamente nas instituições formadoras, onde os alunos aprendem a falar como professores, advogados, engenheiros. Entendendo que a essência da linguagem é dialógica (Bakhtin [1953] 1986, Bakhtin/Volochinov, ([1929] 1988) cada palavra já tem o sentido do outro nela inscrito e cada indivíduo se constitui intersubjetivamente através das palavras do outro. Daí segue-se que as interações acadêmicas ${ }^{11}$ são centrais para o processo: $o$ aluno se afilia a uma ou outra ideologia ou discurso profissional nessas interações, em particular àqueles discursos que tendem a oferecer respostas para as questões que afetam ou afetarão o cotidiano de suas práticas.

O dialogismo postula que a interação é fundamental na vida social. Ela é determinante na construção das identidades discursivas e situadas, que decorrem das orientações momentâneas, locais, circunstanciais, passo a passo, dos participantes ao discurso do outro. ${ }^{12}$ Essas orientações resultam em posicionamentos sociais e relacionais que dependem de poder, status, hierarquia, gênero, etnia que os participantes se atribuem mutuamente (cf Holland et al., 1998). $\mathrm{Na}$ interação, o sujeito pode se posicionar como um agente, isto é, como um sujeito que atua autonomamente, ${ }^{13}$ num jogo de resistência, a fim de causar transformação numa dimensão social ou coletiva, ou pode posicionar-se subalternamente, num jogo de conformi-

11 O processo discursivo motor da socialização profissional é mais facilmente realizado, segundo Mertz (1992), nas universidades de prestígio.

12 Essa premissa faz parte das teorias socioconstrucionistas microanalíticas, como a sociolinguiística interacional (fortemente influenciada pela etnometodologia, e a sociologia interacional de Goffmann) e a sociolinguiística interacional crítica; esta última escaparia da acusação de reducionismo pelo fato de incorporar a dimensão das estruturas sócio-históricas de poder e dominação.

13 A agência não implica autonomia absoluta; acreditamos ser melhor pensar que as respostas do sujeito são formas de autonomia locais restritas relacionais (cf. César, 2002) com propósitos situados, inclusive pessoais. 
KLEIMAN, Angela B. Professores e agentes de letramento: identidade e posicionamento social.

dade ou submissão, na sua orientação às práticas culturais dos grupos dominantes. ${ }^{14}$

\section{IDENTIDADES SITUADAS}

Considerando a extração social de grande parte dos alunos dos cursos de formação de professores, o aluno teria de desenvolver a capacidade discursiva, característica de indivíduos envolvidos em movimentos políticos, para reposicionar-se de uma posição subalterna a uma posição de resistência, autônoma, na e pela qual o sujeito se autoriza em relação ao seu dizer (cf. César, 2002), que, ademais, envolveria a capacidade de encontrar uma "segunda voz" no coro discursivo que forma a comunicação humana (Bakhtin/ Volochinov [1929] 1998; Holland et al., 1998).

Acreditamos que a interação a ser analisada, entre duas educadoras populares, mostra essa busca pela palavra autorizadora. As duas mulheres estão engajadas num processo de construção de uma voz coletiva, posicionando-se como leitoras legítimas ante a entrevistadora acadêmica. A interação foi gravada durante a primeira reunião entre a pesquisadora ${ }^{15} \mathrm{e}$ as educadoras, imediatamente após a pesquisadora perguntar "que tipo de leitor é você?" (cf. Vóvio \& Souza, 2005).

A primeira a falar, Cláudia, responde que é uma leitora crítica e suas palavras são imediatamente corroboradas pela sua colega,

14 Isso não significa que a identidade seja monolítica. Há uma complexa imbricação entre os vários discursos profissionais, escolares e do cotidiano que colaboram na construção da identidade profissional do professor. A inconsistência decorrente da presença de um determinado elemento que esteve ausente ou foi negado em outra situação, aponta para a natureza híbrida, flexível, múltipla das identidades (cf. Hall, 2003) e para a natureza interativa e local do processo de construção identitária.

15 Gravado pela pesquisadora Cláudia Lemos Vóvio, que integra o Grupo Letramento do Professor. 
Daniele. Esse alinhamento solidário envolve o uso de uma estratégia de significação singular, que consiste em tratar como sinônimos os dois diferentes sentidos que elas atribuem ao termo "leitor crítico": segundo Cláudia, ela é uma leitora crítica porque assume uma atitude crítica em relação a toda produção que chega às suas mãos; os livros têm de ser muito adequados, relevantes para seus propósitos ou ela os descarta rapidamente, apenas verifica sua falta de pertinência. A segunda educadora, Daniele, que pega o turno imediatamente depois, considera que ela é uma leitora crítica porque lê tudo antes de criticar, jamais larga um livro antes de terminá-lo, para ter argumentos consistentes baseados na própria leitura.

A seguir, o trecho da interação em questão. Note-se o efeito da repetição do advérbio "mesmo" por Daniele, colaborando para a criação de uma coletividade ou um grupo solidário, coeso, que partilha crenças, hábitos e modos de ler semelhantes, embora as duas ações descritas para chegar a uma idéia global do texto sejam bem diferentes:

(2) CLÁUDIA: eu sou uma leitora muito crítica ... entendeu? porque quando eu leio alguma coisa assim (+) eu gosto de ler muito:: ficção romance poesia ... como quando eu tô lendo algum LIVRO que eu vejo que não tem conteúdo que não tem nada $A$ VER o contexto não bate com o que eu quero né... com o que eu espero que seja o livro ... eu automaticamente deixo o livro de lado eu não leio mais ... tenho mania de ler o começo do livro o meio do livro e o final do livro aí eu SEI se o livro é bom ......./

DANIELE: ... eu Daniele ... ASSIM eu sou igual a Cláudia eu leio Tudo ... de TUDO eu leio ... desde a coisa MAis BOba a da coisa mais científica que seja ... e também tenho o mesmo problema que a Cláudia se eu começo ler um livro e eu vejo que ELE não não abrange os meus conhecimentos ... que ele não vai me favorecer em nada eu continuo lendo até o fiNAL:: ... eu leio ele até o final mesmo sabendo que ele não vai abranger pra mim saber:: o conteúdo daquele livro ... entendeu? ... pra mim poder criticar ele antes antes de terminá-lo ... porque às vezes ele começa de um jeito ... tem um meio diferente e um fim totalmente ... ao contrário ... então eu leio ele inteiro.

No posicionamento dessas mulheres com pouca educação formal, formando um grupo em contraposição à pesquisadora, acadêmica de classe média, não há reconhecimento submisso da cultu- 
ra dominante. Elas se autoposicionam como leitoras, protagonistas de suas histórias de leitura, tal como indica o uso repetido dos pronomes de primeira pessoa singular, diferentemente dos usos da professora Nádia, já discutidos, ou da professora Sheila, uma alfabetizadora participando de um programa de formação inicial para professores alfabetizadores em serviço ${ }^{16}$ de uma prestigiosa universidade pública no estado de São Paulo. O trecho a seguir foi retirado de uma entrevista extensa com Sheila, cujo objetivo era conhecer a história de leitura da entrevistada: ${ }^{17}$

(3) Sheila: /.../ Aí agora esse semestre a gente teve, a gente tá tendo aula de Leitura e Escrita, Leitura e Produção de Texto acho que é,com o professor Jxxx e eu adorei porque ele trouxe assim uns livros muito interessantes pra gente discutir, a gente começou com a llíada, que eu tinha comprado pra ler... /.../ aí eu comecei a ler, mas não acabei, aí a gente foi pra Platão, eu não consegui comprar o livro porque eu não achei, comecei a ler, que eu peguei emprestado, não terminei porque aí ele já foi pra próxima aula e eu não consegui terminar. Fomos pra Dom Casmurro, que eu também tinha comprado pra ler, eu li metade e já mudou de aula e eu guardei a metade sem ler, falei não, mais pra frente eu termino. /.../ Agora a gente vai tá trabalhando os seminários, então eu com $A$ Tempestade de Shakespeare pra ler, eu tô na metade, mas esse eu tenho que terminar porque se não eu não faço o seminário, se Deus quiser eu termino hoje ainda, eu vou falar com ele amanhã.

Uma marcante diferença entre as falas está constituída pelas relações de pessoa estabelecidas no texto, no uso dos pronomes pessoais pelos quais as educadoras populares e a professora se referem a si mesmas e a outras professoras. Cláudia e Daniele se apresentam como sujeitos de suas ações e estados mentais e afetivos, com verbos no presente, com um sentido de permanência, construindo assim uma identidade leitora: eu leio, eu vejo, eu deixo de lado, eu não leio, eu começo, eu continuo, para mim criticar, eu gosto, eu quero, eu

16 Programas que se tornaram necessários após a promulgação da já referida LDB9394/ 1996.

17 Gravado por pesquisadores liderados por A. L. Guedes Pinto, que integra o Grupo Letramento do Professor. 
Filol. lingüíst. port., n. 8, p. 409-424, 2006.

espero, eu sei, eu sou uma leitora muito crítica, tenho mania de ler, eu sou igual, eu leio tudo.

Sheila, por outro lado, apropria-se do eu para revelar sua própria subjetividade ao narrar ações que realizou - eu tinha comprado, eu comecei a ler, consegui comprar o livro, eu peguei emprestado, eu também tinha comprado pra ler, eu li metade, tô na metade - ou para ações que não conseguiu realizar no passado: não acabei, eu não achei, não terminei, não consegui terminar. Quando as ações estão no tempo presente, elas não descrevem ações habituais (eu leio) ou estados permanentes (eu gosto), mas a obrigação futura: eu tenho que terminar, eu não faço, eu termino. A recorrência de formas verbais negativas contribui para o efeito de impotência e passividade de seu relato.

Diferentemente das educadoras populares, que se constituem sujeitos protagonistas pela recorrência do pronome eu, Sheila usa também as formas da primeira pessoa do plural - nós e a gente. Os traços distintivos entre as duas formas da primeira pessoa do plural são a impessoalidade e a amplitude de referência: nós sinaliza o grau máximo de inclusão do eu, o mais pessoal, portanto; ao passo que a gente indica o grau mínimo de inclusão do falante, o mais genérico e impessoal (ver Santos Lopes, 1998). A forma a gente está associada à forma verbal da terceira pessoa, morfemicamente a forma zero, indeterminada, com um significado alargado e, em função desses elementos, é considerada a forma da impessoalidade, a não pessoa (Benveniste, 1976). O uso recorrente da expressão impessoal, genérica, menos inclusiva e, poderíamos dizer, mais distante, para referir-se às ações dela e de suas colegas no curso de leitura - a gente teve, a gente tá tendo, pra a gente discutir, a gente começou, a gente foi, a gente vai tá trabalhando - contribui para o efeito de distanciamento das ações sobre as quais ela aparentemente não teria poder.

A construção de uma identidade leitora parece ser o resultado de um processo de letramento não escolar. As duas educadoras populares não somente se posicionam como leitoras legítimas, autorizando-se em relação à pesquisadora, como também usam a lín- 
gua para construir elos de solidariedade entre elas. Já as professoras, sempre posicionadas subalternamente - em relação aos seus professores universitários por exemplo -, não se representam como leitoras, como membros legítimos dos grupos que representam na escola. Acreditamos que tanto a constituição de uma identidade leitora quanto a resistência a ideologias que posicionam os indivíduos como sujeitos menores, em função de sua extração social e pouca escolarização formal, são elementos-chave para atuar como agente social para a transformação do grupo, para agir como sujeito político que faz parte de uma coletividade em busca da mudança.

\section{COMENTÁRIOS FINAIS}

Aprender a ler e escrever é um processo de construção identitária para os alunos de grupos dominados, mais pobres, de tradição oral, porque envolve a aprendizagem de práticas sociais de outros grupos que são, em sua maioria, alheios aos seus interesses, modos de ação e modos de falar. Daí a relevância de focalizarem-se os aspectos políticos do trabalho do professor que o conceito de mediador apaga e o conceito de agente de letramento ressalta.

A rede de relações semânticas que o conceito estabelece com a ação solidária, com a coletividade e com a autonomia destaca o seu potencial valor empoderador na formação do professor. Ao mobilizar os recursos do grupo e ao promover estrategicamente a participação de todos, segundo as suas capacidades, em prol dos objetivos coletivos, o agente de letramento ajuda, como ator social que é, a criar contextos para que outros atores que se engajarão em atividades relevantes para o grupo venham a se constituir.

Um processo de profissionalização acadêmica no qual o aluno é sempre posicionado subalternamente pelos seus professores, pela mídia, pelo empregador não contribui para a formação de sujeitos autônomos, capazes de decidir qual a melhor ação para uma determinada situação, em vez de aplicar uma receita ou modelo aprendido a qualquer situação. 
Filol. lingüíst. port., n. 8, p. 409-424, 2006.

Assim como a relação subalterna pode ser subvertida pelo profissional, a assimetria institucional que aprisiona professor e alunos em papéis intercambiáveis e imutáveis também pode ser revertida. $\mathrm{O}$ posicionamento autônomo e o rompimento da assimetria são produtos do bom letramento, aquele que, em vez de constituir-se em mais uma barreira para a inclusão social, fortalece os sujeitos que adotam as práticas da cultura escrita na sua vida social. Em outras palavras, a apreensão de práticas da cultura escrita pode contribuir para o fortalecimento (empowering) de professores e alunos quando possibilita que esses indivíduos se reposicionem em relação aos posicionamentos subalternos que frequientemente lhes são impostos.

\section{BIBLIOGRAFIA}

ARCHER, Margaret S. (2000). Being Human: The Problem of Agency. Cambridge: Cambridge University Press.

BAKHTIN, M.M. ([1953]1986) Speech Genres \& Other Late Essays. Ed. By Caryl Emerson \& Michael Holquist, Austin: University of Texas Press.

BATISTA, A. A. G. (1998) Os professores são não leitores? In: MARINHO, M. (Org.) Leituras do Professor. Campinas: Mercado de Letras.

BENVENISTE, E. (1976) Problemas de Lingüística Geral. São Paulo: Nacional, Edusp.

BORGES DA SILVA, Simone B. (2005) Leituras de alfabetizadoras. In: KLEIMAN, Angela B. \& MATENCIO, Maria de Lourdes M. (eds.). Letramento e formação do professor. Práticas discursivas, representações e construção do saber. Campinas: Mercado de Letras.

CERTEAU, M. de (1994) A invenção do cotidiano. Artes de fazer. Rio de Janeiro: Vozes.

CESAR, A. (2002) Lições de abril: construção de autoria entre os Pataxó de Coroa Vermelha. Campinas: Unicamp. Tese de Doutorado inédita.

GUEDES-PINTO, Ana L. (2002) Rememorando trajetórias da professora-alfabetizadora. A leitura como prática constitutiva de sua identidade e formação profissionais. Campinas: Mercado de Letras.

HALL, Stuart. (2003) A identidade cultural na pós-modernidade. Tradução Tomaz Tadeu da Silva e Guacira Lopes Louro. 8. ed. Rio de Janeiro: DP\&A.

HEATH, Shirley B. (1983) Ways with words. Cambridge: Cambridge University Press.

HEESOON, B. (1997) Education and cultivation of democratic human agency. A preliminary exploration. Ethics and education Conference at UBC, on line proceedings. Outline: www. educ.sfu.ca/people/facultyhbai. 
KLEIMAN, Angela B. Professores e agentes de letramento: identidade e posicionamento social.

HOLLAND, Dorothy; LACHICOTTE JR., William; SKINNER, Debra; CAIN, Carole (1998). Identity and agency in cultural worlds. Cambridge: Mass, Harvard University Press.

KLEIMAN, Angela B. (2006) Processos identitários na formação profissional: o professor como agente de letramento. In: CORRÊA, Manoel \& BOCH, F. (Orgs.). Ensino de Língua: representação e letramento. Campinas: Mercado de Letras.

SANTOS LOPES, C. R. (1998) Nós e A Gente no Português Falado Culto do Brasil, D.E.L.T.A., v. 14, n. 2, p. 405-22.

MERTZ, Elizabeth. (1992) Linguistic Ideology and Praxis in US Law School Classrooms Pragmatics 2: 3, p. 325-34.

RIBEIRO, Vera M. (2005) Uma perspectiva para os estudos do letramento: lições de um projeto em curso. In: KLEIMAN, Angela B. \& MATENCIO, Maria de Lourdes M. (Orgs.). Letramento e formação do professor. Práticas discursivas, representações e construção do saber. Campinas: Mercado de Letras.

SOARES, M. B. (1996) Português na escola: história de uma disciplina curricular. Revista da Educação AEC, n. 101, p. 9-26.

. (1997) Sobre os PCN de Língua Portuguesa: algumas anotações. In: MARCUSCHI, E. \& Soares, E. A. L. (Orgs.). Avaliação Educacional e Currículo: inclusão e pluralidade. Recife: Ed. Universitária da UFPE.

VIGOTSKY, L.S. ([1930]1984) A formação social da mente. São Paulo: Martins Fontes.

VOVIO, Claudia Lemos \& SOUZA, Ana Lúcia Silva. (2005) Desafios metodológicos em pesquisas sobre letramento. In: KLEIMAN, Angela B. \& MATENCIO, Maria de Lourdes M. (Orgs.). Letramento e formação do professor. Práticas discursivas, representações e construção do saber. Campinas: Mercado de Letras.

ZIMMERMAN, Don H. (1998) Identity, context and interaction. In: ANTAKI, C. \& WIDDICOMBE, S. (Orgs.). Identities in Talk. London: Sage Publications.

ABSTRACT: This paper contrasts the concepts of literacy teacher and literacy agent, in relation to the literacy acquisition modes of the two groups. Based on interaction and dialogic theory of language, we present data from a large project involving five universities, that show how teachers and popular educators represent and position themselves in their interaction with academic professors and researchers and we argue that the differences point towards the construction of differently situated relational identities.

KEYWORDS: Teacher education; Academic literacy; Social agency. 